and providers, as well as users, to consider carefully services for postnatal mental illness and, in particular, the role of a specialised day hospital. A treatment outcome and cost-effectiveness study of the unit compared with a general practice based service is presently being undertaken. Our experience would suggest, however, that a day hospital with close links to a mother and baby unit, as well as to a community specialist team is likely to provide an optimum service-as well as being a centre for education, research and development.

\section{References}

Cox J. L., Holden, J. M. \& SAgovsky, R. (1987) Detection of postnatal depression, development of the 10-item Edinburgh Postnatal Depression Scale (EPDS). British Journal of Psychiatry, 150, 782-786.
Jones, J., Leneman, L. I. \& McLean, U. (1987) Consumer Feedback for the National Health Service: A literature review. King Edward's Hospital Fund for London.

Margison, F. \& Brockington, I. F. (1982) Psychiatric mother and baby units. In Motherhood and Mental Illness, vol. 1 (eds. I. F. Brockington \& R. Kumar), Academic Press.

OATES, M. R. (1988) The development of an integrated community orientated service for severe postnatal mental illness. In Motherhood and Mental Illness, vol. 2: Causes and Consequences (eds. R. Kumar \& I. F. Brockington), London: Wright.

Royal College of Psychiatrists (1992) Report of the General Psychiatry Section Working Party on Postnatal Mental Illness. Psychiatric Bulletin 16, 519-522.

A full list of references is available on request to Professor Cox.

\title{
The landladies of Fishponds
}

\section{A study of private community care}

\section{StePhen Arnott, Senior Registrar in Psychiatry, Glenside Hospital, Stapleton, Bristol BS16 1DD; and JeanetTe Smith, Senior Registrar in Forensic Psychiatry, Fromeside Clinic, Stapleton, Bristol BS16 1ED}

Over the last four decades there has been a substantial reduction in the number of psychiatric hospital beds. Alternative residential facilities in the community have been developed. These include staffed hostels, group homes and supportive lodgings providing bed and breakfast. While hostels and group homes are often integrated with psychiatric services and run by experienced staff, this may not be the case with the small privately run homes. Anstee (1978, 1985) described two supportive lodging schemes and suggested that such facilities were particularly helpful for people with schizophrenia. However, there has been little further research in this area even though supportive lodgings may constitute a significant proportion of long-stay residential facilities. We know little about the landladies, their background, training, experience and particularly the rewards and frustrations of their work. The extent of psychiatric morbidity and the overall burden of care for these landladies is also unknown.

The aim of the present study was to gather information about the carers, the residents and the level of care provided in these facilities.

\section{The study}

This survey was carried out in a part of Bristol called Fishponds in which Glenside Hospital is situated. The area is largely residential and predominately working class although not very deprived. We identified all supportive lodgings through a comprehensive register circulated by the local social services and compiled and updated regularly by an approved social worker who has over ten years experience of 
resettling psychiatric patients around here. This social worker also acts in a liaison capacity with the landladies (carers) and is the local expert on supportive placements for individuals with psychiatric problems. We believe that this is a complete list of all non-NHS and non-local authority residential provisions and allowed us to perform effectively a census of such resources in Fishponds. We contacted the landladies personally and if they agreed, arranged a visit to their home. We interviewed landladies using a structured questionnaire.

We obtained information about the landladies' background and experience, the overall burden of care and the residential facility itself.

\section{Findings}

We identified 25 supported lodgings providing care for adults aged 16-65 with psychiatric problems (not including learning difficulties). Twenty-four landladies agreed to participate in the study.

\section{The landladies}

The carers were predominantly female ( 20 female: 4 male). The average age was 46 years (range $34-65$ ) and the majority were married (20 married:4 single). All 24 were both owners as well as carers.

Thirteen were registered mental nurses, four enrolled nurses, five nursing auxiliaries and two were doubly qualified. Ten still worked in regular employment in local psychiatric hospitals.

The ethnic background was UK Caucasian in seven, Caucasian Irish in six, Afro-Caribbean in seven and Asian in four. Many of the landladies had cared for their residents for years and obviously established an enduring and supportive relationship, allowing quite vulnerable individuals to live in a community setting. Most of the lodgings were family homes where some of the landladies prided themselves in offering care in a homely setting, quite different from a hospital. Several landladies took their residents on annual holiday with them. One Afro-Caribbean landlady emphasised the therapeutic benefit of providing a culturally appropriate milieu for people of West Indian origin.

Most of the landladies met as a group with the liaison social worker on a regular basis to share information and mutual support.

\section{The establishments}

Seventeen were terraced houses, four were semidetached and three detached residences. Sixteen were late Victorian or Edwardian and six pre-war in construction. All were previously family homes. Most were small in size with 18 having less than five bedrooms, the other six having nine to 11 . Standards of decoration varied. Most of the homes were in better decorative order than the long-stay wards of Glenside, the local Victorian mental hospital, prior to its recent closure.

There were 112 places ( 96 single bedrooms and 16 double bedrooms). Total staff numbers were difficult to assess since many were family members and parttime, but the approximate staff:patient ratio was 0.71. Most of the staff were untrained and few had previous experience working with the mentally ill. Eight $(33 \%)$ homes were registered under the Registered Homes Act (HMSO, 1984). Weekly fees were a standard $£ 185$. All but three residents were funded by State Benefit.

\section{The residents}

There were 97 residents, 60 male and 37 female. There had been a turnover of 28 residents in the past year. Fifteen were described as changes of address, often following antisocial behaviour, such as substance abuse and aggression and 13 were re-admitted to psychiatric hospital. The average length of stay was 39 months (range one week to ten years).

Only two out of the $\mathbf{9 7}$ were in paid employment. Eighty-four had a history of in-patient psychiatric treatment and 46 were regarded as currently mentally ill by their landlady. Seventy-three took antipsychotic medication including 41 who were on depot injections. Seventeen landladies dispensed oral medication to their residents.

Seventeen of the homes had experienced disturbed and challenging behaviour in the last month: verbal aggression in 12; physical aggression in six; damage to property in four; inappropriate sexual behaviour in three; deliberate self-harm in one; other bizarre behaviour in 11. The landladies were characteristically very tolerant of behaviour which on occasion had been more extreme than that seen on the local psychiatric hospital's challenging behaviour ward during the time of the survey.

We looked at contact with other helping agencies. The most recent contact with the local psychiatric team was within the last week, five; within the last month, four; within the last year, seven; and more than one year ago, eight. Twenty-three of the homes had frequent contact with their general practitioner, ten with a community psychiatric nurse acting independently and 19 with a local approved social worker.

\section{Comment}

The present study indicates that landladies continue to provide an invaluable service, offering housing, support and friendship to some of the most severely mentally disabled in our community and highlights the significance of supportive lodgings in our area. 
Despite the apparently high levels of psychiatric morbidity and disturbed behaviour exhibited by these individuals, they are often cared for by untrained staff. In many cases the residents were not in regular contact with local psychiatric services. This will probably change with the establishment of a local consultant led community psychiatric rehabilitation team.

Often the residents lived as part of a family, perhaps deriving the benefits of this lifestyle, yet avoiding the over-involvement which can occur when living with close relatives. Clearly such facilities are not appropriate for everyone with chronic mental illness and for some are needed only for a relatively brief period of time. In general it seems essential to have a comprehensive range of residential facilities, in order to offer appropriate care and realistic choices for each individual.

Historically, Glenside Hospital has had good links with the private landladies in the locality of Fishponds. From the 1970s onwards, landladies who specialised in caring for people with mental health problems evolved in response to both local need and the availability of funding from central government. This free market system paralleled the development of organised resettlement programs such as the Bristol Industrial Therapy Housing Association (Early, 1973).

On 1 April 1993, the Community Care Act (HMSO, 1990) was implemented. This could have serious implications for many landladies who currently run unregistered homes. The Community Care Act requires that all such lodgings are registered, and to meet the new regulations landladies may have to make expensive modifications and employ more staff. As a result some of the smaller homes will no longer be viable. Many of the landladies interviewed in this survey were extremely worried about the future of their homes and had seriously considered the possibility of closure. We are concerned that a valuable community resource could be lost, which might increase the number of people with mental illness who are homeless. This study was conducted prior to the implementation of the Community Care Act and we are planning a followup study to evaluate the impact of the new regulations.

This study demonstrates that it is crucial that psychiatric services around the country recognise the significance of this often invisible community resource. Efforts should be made nationally to identify such homes and their residents, so that ongoing support and guidance can be provided. This will help to promote high standards of care in the community.

\section{Acknowledgement}

We would like to thank Hugh Jupp, ASW, for his help.

\section{References}

ANSTEE, B. H. (1978) An alternative to group homes. British Journal of Psychiatry, 132, 356-360.

(1985) An alternative form of community care for the mentally ill. Health Trends, 17, 39-40.

EARLY, D. F. (1973) Bristol Industrial Therapy Housing Association: a contribution to domestic resettlement. British Medical Journal, 3, 491-494.

HMSO (1984) The Registered Homes Act. London.

(1990) National Health Service and Community Care Act. London. 